\title{
Towards a Model for Driver Information Systems Use in a Developing Country
}

\author{
O.A. Randle ${ }^{1}$, R.M. Kekwaletswe ${ }^{2}$ \\ Sol Plaatje University ${ }^{1}$, University of the Witwatersrand ${ }^{2}$ \\ South Africa
}

\begin{abstract}
This paper conceptualizes a model for the acceptance and use of Drivers Information Systems (DIS), in the context of a developing country. DIS are transport and traffic systems designed to make it easier for government officials and traffic officers to keep track of changes and occurrences within a country's roads and traffic registrations. That is, they are meant to improve the quality of traffic and management of transportation within a country. These systems include online vehicle registration, electronic payment of fines and electronic toll collection services. Although the Driver Information System has been implemented in some developing countries their acceptance and use has not been satisfactory. To this point, informed by the Unified Theory of Acceptance and Use of Technology, Social Cognitive Theory and Organization Culture Theory, this paper conceptualizes a model for the proper acceptance and use of the system.
\end{abstract}

\section{Introduction}

The world is developing into a digital environment and this has influenced traffic and transportation. This influence can be seen through the introduction of Intelligent Transportation Systems (ITS). Transportation has moved from cash based society to an automated society and it has also improved with the drivers license systems, and it is now referred to as Intelligent Transportation System or vehicle Information systems

These systems are supported by Intelligent transportation infrastructures, the ITS has several components but in developing countries such as South Africa some of them have been introduced such as eToll (a system designed to assist government collect revenue from motorists), eNaTIS (which is a system which is intended for users to be able to register their vehicles and update their vehicle details) and Transman (A traffic camera system) while in Nigeria they are currently introducing and implementing the Drivers Information System(DIS).

All these systems are designed to assist the government of the respective countries to control the flow of vehicles and improve the security of lives and properties and also have a better traffic statistical data.
These systems also assist governments in generating revenue through payment of fines, assists in tracking traffic offenders and control the flow of traffic on the major highways [1]. It even helps to improve road security and properties by being able to take videos while monitoring vehicles and road traffic.

With the ever increasing number of vehicles on the roads in the cities and villages, there is need for a method by which drivers can be can be monitored and enforcement of traffic fines can be implemented.

This led to the introduction of the automated driver's license system which was previously done on paper in the various vehicle department offices through Vehicle License officer (VLO) until the introduction of the Drivers Information systems (DIS).

\section{Related Works}

e-Revenue license is the vehicle registration system used in SRI LANKA as a country, the system was developed as a result of the problems which the nation faced due to its cumbersome vehicle registration processes, the problem included the fact that vehicle owners had to go to the designated Vehicle License Officer (VLO) in their province which meant long hours of driving, and even after registering the vehicle the drivers could not get the disk because the VLO still had to take it to the head office to get the vehicle license disc.

This problems led to the introduction of $\mathrm{e}$ revenue license process in 2003, and this allowed the designated VLO to be able to obtain vehicle information, through a centrally located system, and thereby reduced the time being spent from days to hours at the vehicle department in the province, and this helped the country to reduce the number of paperwork being used at the department as well as the long queues. Furthermore the nation of SRI LANKA improved on their vehicle system by making a drive in system where drivers get their licenses renewed within 2 minutes while sited in their vehicle.

In 2010 the system was completely moved to an online system whereby drivers did not need to come to the vehicle department any longer, but could apply for renewal and do the renewal online, pay bills 
online and even get alerts on when their vehicle disc would expire.

The major factors that made the SRI LANKA eRevenue license process were committed leadership, committed staff, unparalleled necessity of the project, having the same staff member throughout the project and finally the gradual implementation of the project.

Even with the success of implementing the system the system is still faced with problems such as the licenses can only be obtained from a registered VLO, it can only be obtained during office hours; they could not verify whether the documents submitted by the users of the systems were originals or forgeries.

Other studies such as Anagnostopoulos et al. have investigated the effect of intelligent license plates to assist the core transport infrastructure systems will toll payments, fee parking, freeway and arterial management systems for vehicle surveillance as well as using the technique to improve security [2].

Yeow et al. have investigated the acceptance of smart ID cards for driver's license such as MyKad, which can be used as a payment technique for fines and registration of vehicles, and this is being implemented in countries such as Hong Kong, India, Oman, and China [3].

Also the study investigated the acceptance of the MyKad by the people of the nations and used 2 theories as the basis, these theories were Technology Acceptance Model (TAM) and the model of Personal Computer Utilization and the Innovation Diffusion theory.

Jean-Claude et al. has investigated the Dedicated Road Infrastructure for Vehicle Safety in Europe (DRIVE) and have defined and developed a framework for the guidelines evaluating ITS projects [4]. Automatic Highway systems (AHS) such as ATIMS have been investigated [5] for on-road surveillance and control of traffic flow which enable easy communication with the traffic department on defaulters, furthermore the study focuses on intelligent transit for effective payment methods

\section{Theoretical Underpinnings}

The theories underpinning this study are discussed below, Researchers such as Sundaravej have suggested that implementing one theory or models not sufficient to be considered as a final model to underpin a research study which concerns intention to use and make use of technology [6]. Therefore this study will aim to integrate several theories and take different vital components from each theory which can be termed as critical success factors.

\subsection{Unified Theory of Acceptance and Use of Technology (UTAUT2)}

UTAUT2 [7] model is an extended version of the UTAUT [7]. UTAUT is a unique model in which it is a combination of 8 different theories. There have been various theories that have explained use and intent to use technology, these theories include Theory of Reasoned Action (TRA) [8] which is the foundation for theories such as technology Acceptance Model (TAM) [10], Theory of Planned Behavior (TPB) [9]. It also led to the Task Technology Fit Model [11], Innovation Diffusion Theory [12].

These above mentioned theories produced an imbalance, confusion, and contradicted each other. These contradictions let to the creation of the Unified Theory of Acceptance and Use of Technology (UTAUT) by Vankatash which comprises all the 8 theories that focus on use and intent to use. This theory was tested [7] to understand why individuals use or do not use technology.

The other theories that combine to develop the UTAUT include all the theories listed above and Social Cognitive Theory (SCT) [16], Model of PC Utilization (MPCU) [13]. The aim of the UTAUT is to explain the users intentions to use an information system and the consequent usage behavior [7].

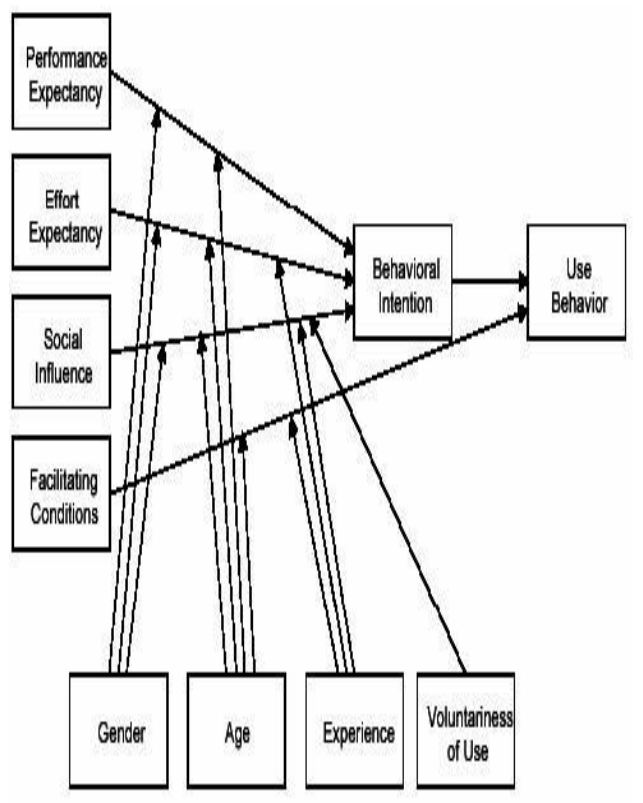

Figure 1.UTAUT Model [7]

The table below provides a unified view to explain user's acceptance of new technology so that researchers no longer need to pick and choose one model while ignoring the contributions of other models [7]. 
Table 1. Models and Elements of Individual Acceptance

\begin{tabular}{|c|c|c|}
\hline $\begin{array}{l}\text { AUTHOR } \\
\text { AND YEAR } \\
\end{array}$ & $\begin{array}{l}\text { MODELS AND } \\
\text { THEORIES }\end{array}$ & ELEMENTS \\
\hline $\begin{array}{l}\text { Fishbein and } \\
\text { Ajzen(1975) }\end{array}$ & $\begin{array}{l}\text { Theory of Reasoned } \\
\text { Action (TRA) to } \\
\text { measure performance } \\
\text { and behavioral } \\
\text { intention }\end{array}$ & $\begin{array}{l}\text { Attitude } \\
\text { Subjective Norm }\end{array}$ \\
\hline $\begin{array}{l}\text { Venkatesh and } \\
\text { Davis (2000) }\end{array}$ & $\begin{array}{l}\text { Technology } \\
\text { Acceptance Model } \\
\text { 2(TAM2) which is } \\
\text { an extended TAM }\end{array}$ & $\begin{array}{l}\text { Perceived Usefulness, } \\
\text { Perceived Ease of Use } \\
\text { Subjective Norm } \\
\text { Experience } \\
\text { Voluntariness } \\
\text { Image } \\
\text { Job Relevance } \\
\text { Output Quality } \\
\text { Result } \\
\text { Demonstrability }\end{array}$ \\
\hline $\begin{array}{l}\text { Daviset } \\
\text { al.,1992 }\end{array}$ & $\begin{array}{l}\text { Motivational } \\
\text { Model (MM) to } \\
\text { describe behavior of } \\
\text { technology adoption } \\
\text { and use }\end{array}$ & $\begin{array}{l}\text { Motivation(Extrinsic } \\
\text { and Intrinsic }\end{array}$ \\
\hline Ajzen (1991) & $\begin{array}{l}\text { Theory of } \\
\text { Planned } \\
\text { Behavior(TPB) to } \\
\text { determine behavior } \\
\text { and intention }\end{array}$ & $\begin{array}{ll}\text { Attitude } & \text { Subjective } \\
\text { Norm } & \\
\text { Perceived } & \text { Behavioral } \\
\text { Control } & \end{array}$ \\
\hline $\begin{array}{l}\text { Taylor and } \\
\text { Todd (1995) }\end{array}$ & $\begin{array}{l}\text { Combined TAM } \\
\text { and TPB }\end{array}$ & $\begin{array}{l}\text { Perceived Usefulness } \\
\text { Perceived Ease of Use } \\
\text { Attitude } \\
\text { Subjective Norm } \\
\text { Perceived Behavioral } \\
\text { Control }\end{array}$ \\
\hline $\begin{array}{l}\text { Thompson et } \\
\text { al., } 1991\end{array}$ & $\begin{array}{l}\text { Model of PC } \\
\text { Utilization(MPCU) } \\
\text { to determine } \\
\text { behavior of PC usage }\end{array}$ & $\begin{array}{l}\text { Social Factor Affect } \\
\text { perceived } \\
\text { Consequences. } \\
\text { Facilitating } \\
\text { Conditions } \\
\text { Habits } \\
\end{array}$ \\
\hline $\begin{array}{l}\text { Rodgers } \\
(1962)\end{array}$ & $\begin{array}{l}\text { Innovation Diffusion } \\
\text { Theory(IDT) }\end{array}$ & $\begin{array}{l}\text { Relative Advantage } \\
\text { Compatibility } \\
\text { Complexity } \\
\text { Trialability } \\
\text { Image } \\
\text { Voluntariness of Use }\end{array}$ \\
\hline $\begin{array}{l}\text { Bandura } \\
(1986)\end{array}$ & $\begin{array}{l}\text { Social Cognitive } \\
\text { Theory(SCT) to } \\
\text { determine usage of } \\
\text { Information Systems }\end{array}$ & $\begin{array}{l}\text { Encouragement of } \\
\text { Others } \\
\text { Use of Others } \\
\text { Support } \\
\text { Self-Efficacy } \\
\text { Performance Outcome } \\
\text { Expectations } \\
\text { Personal Outcome } \\
\text { Expectations } \\
\text { Affect }\end{array}$ \\
\hline
\end{tabular}

In 2012, Venkatesh and others extended UTAUT to pay specific attention to the consumer use context instead of its original purpose which was technology acceptance and use of employees [7].

UTAUT was extended by including Hedonic Motivation, Price Value and Habit. From this UTAUT2 has improved the variance of behavioral intention by $18 \%$ use of technology by $12 \%$ [7]. The definition of the UTAUT2 elements is represented in the Table below.
Table 2. Definition of the UTAUT2 elements

\begin{tabular}{|c|c|c|}
\hline ELEMENT & DEFINITION & PAPERS \\
\hline $\begin{array}{l}\text { Performance } \\
\text { Expectancy }(\mathrm{PE})\end{array}$ & $\begin{array}{l}\text { Similar to TAM's } \\
\text { perceived } \\
\text { usefulness, it is the } \\
\text { perception of } \\
\text { individuals that } \\
\text { using the system } \\
\text { will improve their } \\
\text { performance. } \\
\text { It is the benefit } \\
\text { received from } \\
\text { using the } \\
\text { technology } \\
\text { performing } \\
\text { activities }\end{array}$ & $\begin{array}{l}\text { Min, Ji \& Qu } \\
(2008) \\
\text { Jambulingam } \\
(2013) \\
\\
\text { Venkatesh et al., } \\
2012\end{array}$ \\
\hline $\begin{array}{l}\text { Effort } \quad \text { Expectancy } \\
\text { (EE) }\end{array}$ & $\begin{array}{l}\text { It is the easiness in } \\
\text { using a technology }\end{array}$ & $\begin{array}{l}\text { Venkatesh \& } \\
\text { Brown (2001) as } \\
\text { cited in Venkatesh } \\
\text { et al., 2011 }\end{array}$ \\
\hline Social Influence (SI) & $\begin{array}{l}\text { The Perception of } \\
\text { an individual } \\
\text { where significant } \\
\text { others such as } \\
\text { relatives and peers } \\
\text { believes the } \\
\text { individual should } \\
\text { adopt } \\
\text { technology }\end{array}$ & $\begin{array}{l}\text { Fishbein and } \\
\text { Ajzen (1975) } \\
\text { As cited in Leong, } \\
\text { Hew, Tan and Ooi } \\
(2013)\end{array}$ \\
\hline $\begin{array}{l}\text { Facilitating } \\
\text { Conditions (FC) }\end{array}$ & $\begin{array}{l}\text { The perception of } \\
\text { an individual that } \\
\text { technical and } \\
\text { organizational } \\
\text { infrastructure } \\
\text { exists to support } \\
\text { the use of } \\
\text { technology }\end{array}$ & $\begin{array}{l}\text { Venkatesh et al., } \\
2003\end{array}$ \\
\hline $\begin{array}{l}\text { Hedonic Motivation } \\
(\mathrm{HM})\end{array}$ & $\begin{array}{l}\text { The experience of } \\
\text { fun or pleasure } \\
\text { when using } \\
\text { technology } \\
\text { The perceived } \\
\text { enjoyment when } \\
\text { using a technology, } \\
\text { despite the } \\
\text { performance } \\
\text { consequences that } \\
\text { may be expected }\end{array}$ & $\begin{array}{l}\text { Brown and } \\
\text { Venkatesh (2005) } \\
\begin{array}{l}\text { Davis, } \\
\text { and } \\
(1992)\end{array}\end{array}$ \\
\hline Price Value (PV) & $\begin{array}{l}\text { The trade-off } \\
\text { between the cost of } \\
\text { using the } \\
\text { technology and the } \\
\text { perceived benefits }\end{array}$ & $\begin{array}{l}\text { Dodds, Monroe } \\
\text { and Grewal (1991) }\end{array}$ \\
\hline Habit (HT) & $\begin{array}{l}\text { Automatic } \\
\text { behaviors } \\
\text { performed due to } \\
\text { learning. } \\
\text { It is a natural } \\
\text { behavior of a } \\
\text { person viewed in } 2 \\
\text { different ways: } \\
\text { As an earlier } \\
\text { behavior } \\
\text { As an automatic } \\
\text { behavior }\end{array}$ & $\begin{array}{l}\text { Limayem et al., } \\
2007 \\
\text { Kim and Malhotra } \\
(2005)\end{array}$ \\
\hline
\end{tabular}

Since the introduction of UTAUT2 in 2012, there has been limited research in the UTAUT2 
implementation literature. Lewis et al. employed the UTAUT2 model to address the adoption of information technology in the universities classrooms of the United States.

They found that PE, EE, SI and HT were significant factors in the context of instructors' use of technology purposes. Ally and Gardiner (2012) applied the UTAUT2 in their conceptual paper. They also integrated the TAM model and developed new variables to specifically explain individual's behavioral intentions towards the use of smart mobile devices. Their focus group was postgraduate students in Australia.

The present study applies 5 of the seven constructs of UTAUT2 and combine them with the Social Cognitive Theory (SCT) and Organization Culture Theory (OCT) to determine whether the factors influences the behavioral intention of employees using DIS systems.

\subsection{Social Cognitive Theory}

The social cognitive theory was developed by Bandura in 1977 and is widely accepted for understanding individual acceptance [15], [16], [24]. It operates on the belief or basis that environmental influences such as social pressure and personal factors are reciprocally determined. Individuals choose the environments in which they exist in addition to being influenced by the environment. Bandura suggests there are 2 sets of expectations as the major cognitive forces guiding behavior [24].

The first set relates to outcomes (Individuals are more likely to undertake behaviors they believe will result in valued outcomes rather than those they fell would not. The second set of expectations comprises of self-efficacy (self-efficacy influences choices about what behaviors to undertake, the effort and persistence exerted in the face of obstacles to the performance of those behaviors. This research will include self-efficacy as a critical success factor.

The Social Cognitive Theory has 3 major aspects (person, behavior, environmental), self-efficacy is an aspect of behavioral aspect. Bandura defines selfefficacy as peoples judgment of their capabilities to organize and execute courses of action required to attain designated types of performances [16]. It is concerned not with the skills one has but with judgments of what one can do with whatever skills one possess.

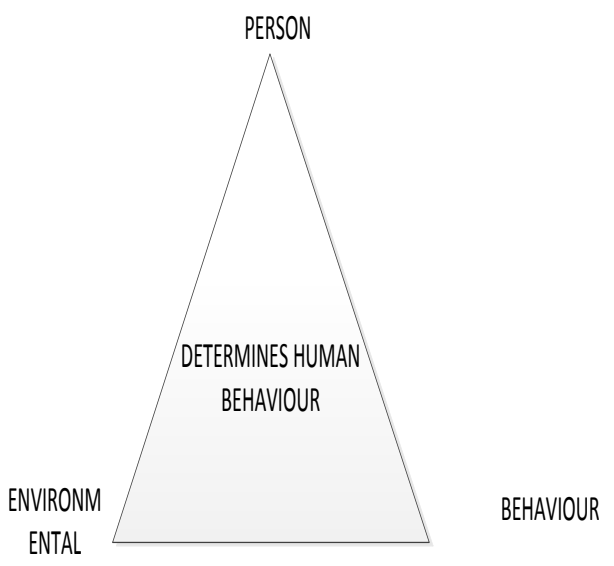

Figure 2. Social Cognitive Theory [16]

Self-efficacy refers to ones judgment of his/her capabilities to perform a type of action that is required to achieve a particular outcome and is not necessarily the skills one possesses but the judgment that one can achieve with a particular skill [16] also self-efficacy is an individual perception of one's own ability to perform a task using a computer. Bandura noted the easier a system is to interact with, the greater the users sense of efficacy [16].

\subsection{Organizational Culture Theory}

Culture can be regarded as the values and beliefs of individuals or groups of people. It is the root of social behaviors such as arts, beliefs and behavioral patterns. Culture can be based on various units and therefore there are various types of culture which include national culture, organizational culture, professional culture, functional culture and team culture. Researchers such as Couger [17], Choe [18] have focused on the effects of culture on organization. An individual's work behavior is influenced by a cultural norm such as supernatural, national or organizational.

Researchers such as Harrington and Guinaraes, and Dasgupta et al. have focused on the roles of organizational culture on absorptive capabilities, information technology success, Information Technology adoption and diffusion [19]. Demison and Mishra identified four traits as second order constructs for organizational culture which are performance expectancy, effort expectancy, social influence and facilitation conditions. 
Uncovering the Levels of Culture

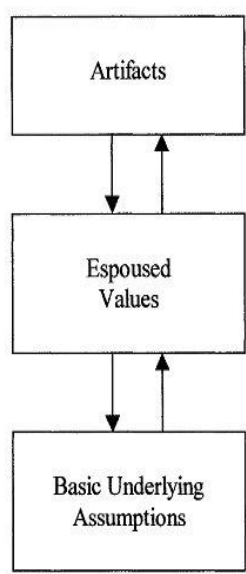

Visible organizational structures and

processes

(hard to decipher)

Strategies, goals, philosophies (espoused justifications)

Unconscious, taken-for-granted beliefs, perceptions, thoughts, and feelings

(ultimate source of values and action)

Figure 3. Organizational Culture theory [14]

Figure 3 provides a figurative explanation of the steps involved in Organization Culture theory which shows the unconscious belief, perceptions which the individuals who use the system have in their mindset. It further shows that there are goals and philosophies which the people who use the system have imbibed or cultivated, and also a focus on the organizational structures are vital, and the diagram also shows that the artifacts, espoused values and basic underlying assumptions are all interrelated.

\section{A Research Model for Drivers Information System Use in a Developing Country}

Figure 4 shows the relationships between constructs and the conceptualized correlations and hypotheses for the study.

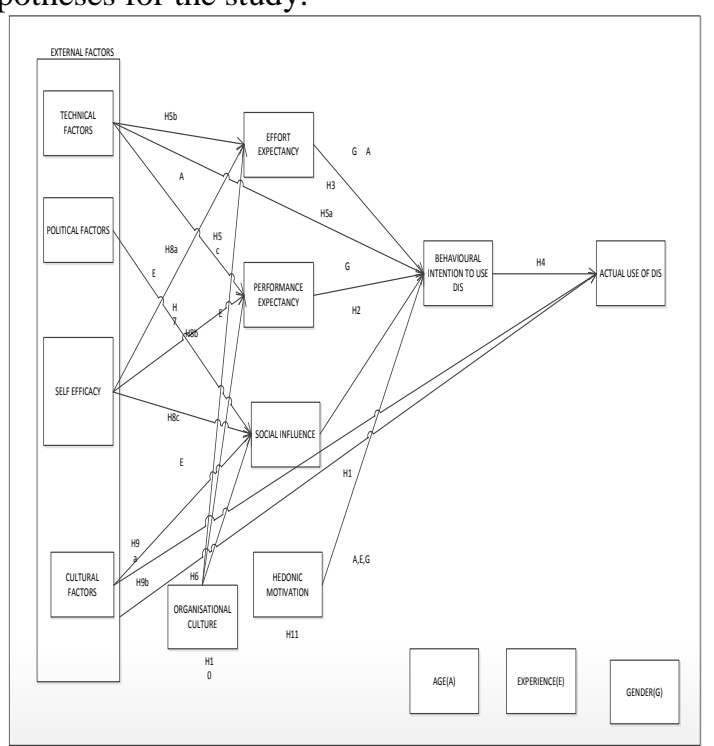

Figure 4. A Conceptual Research Model for DIS use
They show the proposed concepts and factors influencing the acceptance and use of Driver Information Systems in the context of a developing country.

\section{Research Hypotheses}

\subsection{Social Influence}

Venkatesh et al. strongly believed that behavioral claims or intentions have significant influence on the utilization of technology or an information system [7]. Several models designed from psychological theories suggest that one's behavior is highly influenced by one's personal or individual intentions.

For an individual to use the DIS systems the individual should have the intention to use the system to achieve a particular objective or goal. This implies that what an individual has heard about the DIS system from the society can affect his/her decision to use the system. The hypothesis for this is;

\section{H1: Social Influence has a positive influence on behavioral intention to use DIS}

Social influence is operationalized through the following items:

Social Influence - (Scale 1 (strongly disagree) - Scale
5 (strongly Agree)
People who are important to me think I should use
DIS
People who influence my behavior think I should use
DIS
My friends/staff are helpful in the use of DIS
In general the university supports the use of DIS

\subsection{Performance Expectancy}

Researchers such as Vankatesh et al., have suggested that performance expectancy positively influences behavioral intention provided it is moderated by age and gender [7]. This is in accordance with other researchers such as Davis, [10] which have investigated and researched and have concluded that perceived ease of use has a positive impact on behavioral intention. In this study Performance Expectancy means that employees will be expected to use DIS to perform their duties. This suggests that if employees performances were to be reviewed using the DIS, they would be forced to use the system. This leads to the second hypothesis;

H2: Performance expectancy has a positive influence on behavioral intention to use DIS.

Performance Expectancy is operationalized through the following items: 


\begin{tabular}{l}
\hline $\begin{array}{l}\text { Performance Expectancy - (Scale 1 (strongly } \\
\text { disagree) - Scale 5 (strongly Agree) }\end{array}$ \\
\hline I find DIS useful \\
\hline Using DIS enables me accomplish my work quickly \\
\hline $\begin{array}{l}\text { Using DIS increases the effective use of my time in } \\
\text { handling duties }\end{array}$ \\
\hline $\begin{array}{l}\text { Using DIS increases the quality of my work and time } \\
\text { put into work }\end{array}$
\end{tabular}

\subsection{Effort Expectancy}

The study of Davis et al. [10], and Venkatash and Davis [7] also observed that behavioral intention is positively influenced by effort expectancy provided they are moderated by age, gender, experience with technology. This means if the DIS system is easy to use then individuals will use the system because not much effort will be required to use the system. From this research the third hypothesis is drawn:

\section{H3: Effort Expectancy has a positive influence on behavioral intention to use DIS}

Effort Expectancy is operationalized through the following items:

\begin{tabular}{l}
\hline $\begin{array}{l}\text { Effort Expectancy -(Scale 1(strongly disagree)-Scale } \\
\text { 5(strongly Agree) }\end{array}$ \\
\hline My interaction with DIS is clear and understandable \\
\hline It is easy for me to be skilful at using DIS \\
\hline Learning to use DIS system is easy for me \\
\hline $\begin{array}{l}\text { I find it easy to get DIS system to do what I want it } \\
\text { to do }\end{array}$
\end{tabular}

\subsection{Behavioral Intention}

The research conducted by Tibenderana and Ogao [22] suggest that UTAUT is very predictive for behavioral intention to enlist actual usage of technology. Therefore the fourth hypothesis is drawn from it as follows:

\section{H4: Behavioural Intention has a positive influence effective usage of DIS}

Behavioral Intention is operationalized through the following items:

\begin{tabular}{|l|}
\hline $\begin{array}{l}\text { Behavioural Intention to use - (Scale 1(strongly } \\
\text { disagree) - Scale 5(strongly Agree) }\end{array}$ \\
\hline I intend to use and Improve my skills of DIS \\
\hline $\begin{array}{l}\text { I predict I would use other components / } \\
\text { functionalities of DIS if given a chance }\end{array}$ \\
\hline $\begin{array}{l}\text { I plan to use all components/functionalities of DIS } \\
\text { used in other departments }\end{array}$
\end{tabular}

\subsection{Technical Factors}

Social, political, technical, individual factors are grouped as external factors. These factors affect the actual usage of the system and could have a positive or negative impact on the system. Technical factors can have an impact on the behavioral intention and effective usage [7]. And it shows that effort expectancy and performance expectancy are related to the technical factors. If the proper technology is in place, people would find the DIS easy to use. Also since [7], [10] established that both effort and performance expectancy positively influence behavioral intention. Furthermore if the proper technology is in place both efforts expectancy and performance expectancy will positively influence behavioral intention to use DIS. This study drew the following hypothesis. $\mathrm{H} 5 \mathrm{a}-\mathrm{H} 5 \mathrm{c}$ are developed as

\section{H5: Technical Factors have a positive influence on behavioral intention to use DIS}

If there is proper technology or proper support for the DIS system users will find it easy to use the DIS system, the user of the DIS system will find the system easy to use and free of effort and would want to use the system more frequently, which leads to hypothesis $\mathrm{H} 5 \mathrm{~b}$ :

\section{H5b: Technical factors positively influence effort expectancy for DIS usage}

If the proper technology is in place and the proper networks are available it will positively influence the users of DIS to use the system and it will enable the individual to believe that he or she can attain their goals using DIS. This leads to H5c:

\section{H5c: Technical factors positively influence performance expectancy for DIS effective usage.}

Technical factor is operationalized through the following items:

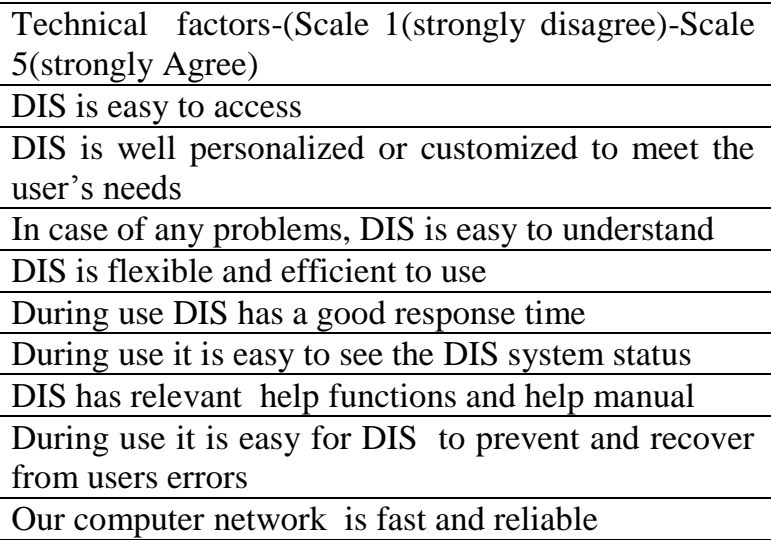




\subsection{External Factors}

The external factors such as social, political, technical and individual factors have been predicted to have a positive influence on the usage of DIS. Therefore the following hypothesis is deduced:

\section{H6: External factors such as culture has a direct influence on effective usage}

External Factors is operationalized through the following items:

External factors - (Scale 1 (strongly disagree) - Scale 5 (strongly Agree)

The DIS developing team provides support and consultation services

My role and position necessitates me to use DIS

Generally there is a culture of resistance in my university that affects the use of DIS

My attitude towards computers influences me to use DIS

My satisfaction with DIS makes me use it

Motivation from my supervisors makes me to use DIS

The computers we use makes smooth use of DIS

The Political influence in my country makes me to use DIS

\subsection{Political Factors}

It is suggested that some of the external factors will have a strong influence on other factor, such as political influences are embedded in the user's day to day activities. Their activities are not only influenced by the people they perceive important [7]. The political climate can have a direct influence on the use of DIS. Hence, the next hypothesis is drawn (H7)

\section{H7: Political factors have a significant effect on user's social influence when using DIS}

Political factor is operationalized through the following items:

Political factors - (Scale 1(strongly disagree) - Scale 5 (strongly Agree)

Government policies

Political Influence

\subsection{Self Efficacy}

Researchers [13] have suggested that personal beliefs play a vital role for users of the system improving individual beliefs about their ability to perform certain tasks successfully. It further suggests that when users believe a system is easy to use, they will use it but if they feel the system is difficult to use, they will turn away from the system. Which means users perspective influence social beliefs? This means that individual's decisions on DIS are vital in deciding to use the DIS system and can affect the decision to use DIS or not to use DIS. This leads to the next hypothesis (H8a-c)

\section{H8a: Self Efficacy will positively influence effort expectancy to use DIS}

Improving individual's belief in themselves to perform certain task will encourage the individuals to use the DIS and this will also improve their performance expectancy and ensure they use the DIS system for more tasks.

\section{H8b: Self Efficacy will positively influence performance expectancy to use DIS}

Improving individual's belief in them to perform certain tasks using DIS will encourage them to use DIS and also will affect social influence by making colleagues aware of the DIS usage and this will increase the number of individuals using the DIS.

\section{H8c: Self Efficacy will positively influence social influence to use DIS}

Self-efficacy is operationalized through the following items:

Self - Efficacy - (Scale 1 (strongly disagree) - Scale
5 (strongly Agree)
I feel confident working on DIS
I would use DIS if I could use the computer
efficiently
I would use DIS if I was helped at the beginning
I would use DIS if it had a built - in facility for
assistance
I would use DIS if someone showed me how to use it
for the first time

\subsection{Cultural Factors}

Ajzen and Fishbein [8] argue that the culture of an individual influences his or her normative belief and socially influences. They put that culture influences various aspects of individual's lives that range from subjective attributes like attitudes, beliefs, and opinions.

This therefore means culture directly or indirectly influences the way people live, people's interactions and their social standards. Culture also influences the intention to use technology [13], also depending on the social environment at the work places, some individuals would refuse to use the system while others will use the system. It is possible for culture to influence social behavior towards DIS and also contribute to what determines or makes individuals 
to use or not use the system. Therefore this study provides the next hypothesis (H9a-c) as follows

Cultural factors will influence the user's decision to use DIS because it will enable individuals to have the concept that those who are most important to them expect or think they should use DIS. This leads to the next hypothesis $\mathrm{H} 9 \mathrm{a}$;

\section{H9a: Cultural factors have significant effect on social influences to use DIS}

Cultural factors will influence users' decision to use DIS because it will enable individuals to have the concept that those who are most important to them expect or think they should use DIS. This leads to the next hypothesis $\mathrm{H} 9 \mathrm{~b}$ :

\section{H9b: Cultural factors significantly influence behavioral intention to use DIS}

Cultural factor is operationalized through the following items:

\begin{tabular}{|l|}
\hline Cultural Factors -(Scale 1(strongly disagree)-Scale \\
5(strongly Agree) \\
\hline Rules \\
\hline Practices \\
\hline
\end{tabular}

\subsection{Organizational Factors}

Several researchers have suggested that Organizational Factors play a significant role in the use of Technology. Researchers such as Kalema, have suggested that the most important critical success factor for any component of an ERP is Organizational factors. Organizational factors are vital for the successful implementation of DIS.

If users perceive that they have enough competence to use DIS, their perceived ease of use will increase and also would their perceived usefulness to DIS and this in turn positively impacts on their behavioral intention to use DIS. This leads to the following Hypothesis (H10a-c). Organizational factors have an influence on the individual's effort expectancy, this is because once the university trains the employee in using the DIS system, the institution expects the individual to be able to use the system with ease. This therefore leads to hypothesis $\mathrm{H} 10 \mathrm{a}$;

\section{H10a: Organizational factors have a positive influence on effort expectancy}

Organizational factors such as training the employee, and making employees project champion will encourage the employee to use DIS and it will enlighten the employee to understand that using the system will enable him/her to attain their goals.H10b;
H10b: Organisational factors have a positive influence on performance expectancy

With the provision of training for employees on the usage of DIS, and since the employees are using the system regularly, a new employee will use the system because he/she see other important employees using the DIS system. This leads to the next hypothesis $\mathrm{H} 10 \mathrm{c}$;

\section{H10c: Organisational factors have a positive} influence on social influence

Organizational factor is operationalized using:

\begin{tabular}{|l|}
\hline $\begin{array}{l}\text { Organizational Factors -(Scale 1(strongly } \\
\text { disagree)-Scale 5(strongly Agree) }\end{array}$ \\
The rule forces me to use DIS \\
The university orders employees to use nothing \\
else other than DIS \\
After completing my tasks I input the details into \\
DIS
\end{tabular}

\subsection{Hedonic Motivation}

Researches such as Brown and Venkatesh, have suggested that hedonic motivation influences technology acceptance and the use directly of technology (Van der Heijden, 2004; Thong et al 2006).It is further suggested that hedonic motivation is the fun and pleasure derived from using a technology, and it is an important determinant of technology acceptance and use. Studies have also suggested that perceived enjoyment (hedonic motivation) from the use of DIS can influence the acceptance and use of DIS. Therefore this leads to hypothesis 11 which states that:

\section{H11: Hedomic motivation has a positive influence} on behavioral intention to use DIS.

Hedonic motivation is operationalized through the following items:

Hedonic motivation -(Scale 1(strongly disagree)Scale 5(strongly Agree)

Using DIS is fun

Using DIS is enjoyable

Using DIS is entertaining

Using DIS gives me pleasure

\subsection{Influences of Moderating Factors}

Four moderating factors (gender, age, experience with technology and voluntariness to use) have been predicted and tested and they were found to have moderating effect on the models constructs [7]. These factors are discussed below: 
5.12.1. Gender. It was discovered to have a moderating effect on performance expectancy, social influence and effort expectancy. Gender is vital in this study because it is under the assumption that it will positively influence on the 3 constructs as was in the case of the original UTAUT model. From this understanding the hypothesis $\mathrm{H} 10 \mathrm{a}-\mathrm{c}$ was drawn as follows:

Researchers such as Venkatesh et al. [7], have suggested that there is a relationship between performance expectancy and intention will be moderated by gender. It further suggests that men tend to be highly task-orientated which leads to the next hypothesis

H12a: The influence of performance expectancy on behavioral intention will be moderated by gender in such a way that it will be stronger for male users of DIS

Venkatesh et al., 2000 suggests that effort expectancy is more salient for women than for men and therefore leads to the next hypothesis.

H12b: The influence of effort expectancy on behavioral intention will be moderated by gender in such a way that it will be stronger for male users of DIS

Theories such as UTAUT suggest that women tend to be more sensitive to others opinion and therefore find social influence to be more salient when forming an intention to use new technology [22].

H12c: Social influence's effect on behavioral intention to use DIS will be moderated by gender in such a way that it will be stronger for female users of DIS.

Researchers such as Lee et al., have suggested that gender have been found to be associated with consumer technology innovativeness, and have suggested that early technology use will be higher in young men, which leads to the next hypothesis.

H12d: The influence of hedonic motivation on behavioral intention will be moderated by gender in such a way that it will be stronger for male users of DIS

3.5.2. Age. Various studies such as have proven that young users use technology and are more comfortable with technology that adult or aged people [7]. This suggests that the young users are more prone to explore or have interest in new technology. Age is a moderating factor and its impact needs to be tested on performance expectancy, effort expectancy and social influence.
Researchers such as Venkatesh et al., have suggested that there is a relationship between performance expectancy and intention will be moderated by age [7]. It further suggests that men tend to be highly task-orientated which leads to the next hypothesis:

H13a: The age of an individual has a positive impact on his or her perception of performance expectancy to use DIS such that the perception is greater in younger users of the system.

Venkatesh et al. suggests that effort expectancy is more salient for women than for men and therefore leads to the next hypothesis [7].

H13b: The influence of effort expectancy is positive on behavioral intention and it will be moderated by age such that it is greater in younger users of the system

Theories such as UTAUT suggest that women tend to be more sensitive to others opinion and therefore find social influence to be more salient when forming an intention to use new technology [22].

H13c: The effect of social influence on behavioral intention will be significantly moderated by age such that the impact is greater in younger users of the system

Researchers such as Lee et al. have suggested that gender have been found to be associated with consumer technology innovativeness, and have suggested that early technology use will be higher in young men, which leads to the next hypothesis.

H13d: The effect of Hedonic motivation on behavioral intention will be significantly moderated by age such that the impact is greater in younger users of the system.

3.5.3. Experience with Technology. Venkatesh et al. suggest that frequent and more experienced users of technology would use technology effectively [7]. DIS is a web - based tool which suggests that users that have experience with web-orientated tools will effectively use DIS compared to the counterparts who do not have such experience. This leads to the following hypothesis Venkatesh et al. suggests that effort expectancy is more salient for women than for men and therefore leads to the next hypothesis.

H14a: Individual with prior experience of web based tools will have high effort expectancy with the DIS system

Researchers such as Venkatesh et al., have suggested that there is a relationship between performance 
expectancy and intention will be moderated by age [7]. It further suggests that men tend to be highly task-orientated which leads to the next hypothesis.

H14b-Individual with prior experience of web based tools will have high performance expectancy with the DIS system

UTAUT also suggests that women tend to be more sensitive to others opinion and therefore find social influence to be more salient when forming an intention to use new technology [22].

H14c: Individual with prior experience of web based tools will moderate social influence to enlist behavioral intention to use DIS system

Researchers such as Lee et al., have suggested that gender have been found to be associated with consumer technology innovativeness, and have suggested that early technology use will be higher in young men, which leads to the next hypothesis.

H14d: Individuals with prior experience of web based tools will have a higher hedonic motivation with the DIS system.

With the preceding hypotheses to be tested and the concepts validated, this paper conceptualizes the model for acceptance and use of Driver Information Systems as follows;

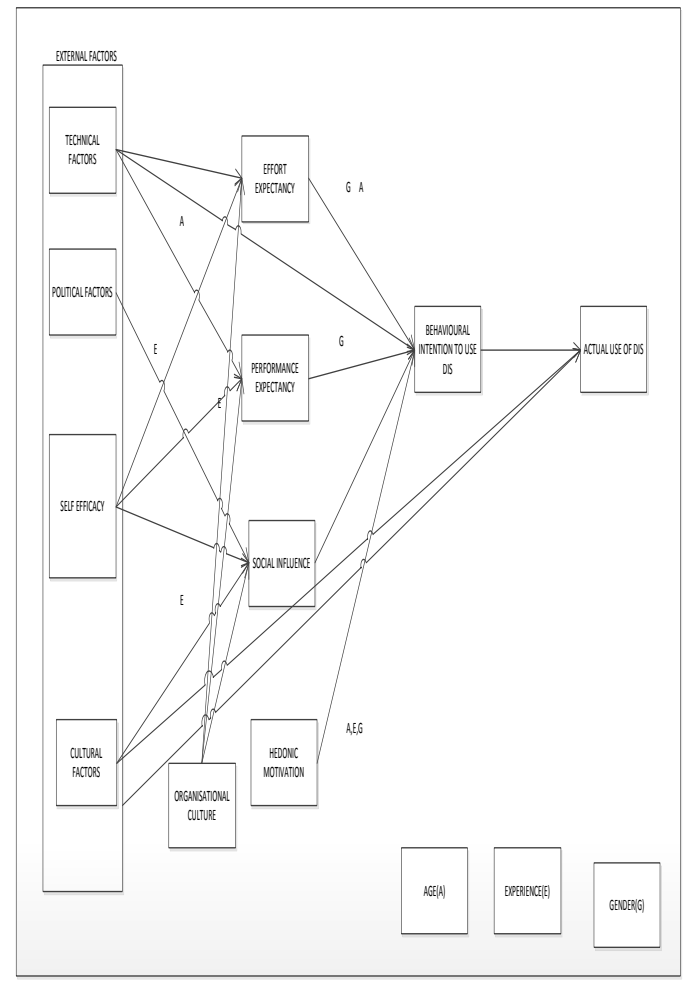

Figure 5. Conceptual Model for DIS use in Developing Countries
In this model, the following factors - technical, political, self-efficacy, external, cultural, effort expectancy, performance expectancy, social influence, organization culture and hedonic motivation - are conceptionalized to influence the behavioral intention to use DIS and subsequently the actual use of DIS.

\section{Conclusion}

DIS are transport and traffic systems designed to make it easier for government officials and traffic officers to keep track of changes and occurrences within a country's roads and traffic registrations. That is, they are meant to improve the quality of transportation and management of transportation within a country. These systems include online vehicle registration, electronic payment of fines and electronic toll collection services. The Driver Information System has been implemented in some developing countries; however, their acceptance and use has not been satisfactory. To this point, this paper conceptualized a model for use of a Drivers Information Systems (DIS), in the context of a developing country.

This paper concludes that if considered well, these factors - technical, political, self-efficacy, external, cultural, effort expectancy, performance expectancy, social influence, organization culture and hedonic motivation - will positively influence the behavioral intention to use DIS and subsequently help improve the actual use of DIS.

\section{References}

[1] J. Rajapakse, A Van der vyver, E. Hommes, 2012. eGovernment Implementation in developing countries: success and failure, two case studies. In the proceedings of ICIAFA-IEEE, pp 95-100

[2] C. N. Anagnostopoulos, V. Anagnostopoulos, V. Loumos, E. Kayafas, 2006. A License Plate recognition algorithm for Intelligent transport System Application. Journal of transport Systems, pp23-34

[3] P. H. P. Yeow, W. Hong, S. Loo, C. C. Hang, 2007. Accepting Multipurpose 'Smart' identity cards in a developing country. Journal of urban technology. Volume 14, No 1, pp 23-50.

[4] T. Jean-Claud, G. Rogova, Y. Jun, 2004. Evaluating the benefits and Cost of ITS elements. Economic Impacts of Intelligent Transportation Systems: Innovations and case Studies. Vol.8, pp 571-603

[5] B. J. Kanninen, 1.996 .Intelligent Transportation System: An Economic and Environmental Policy Assessment. Elsevier, pp. 12-19

[6] T. Sundaravej, 2009. Empirical Validation of Unified theory of Acceptance and Use of technology model. Info Reporter. ICT and electronics in South Africa 2012. 
Available from http://www/southafrica.info. [Accessed 10 September 2012]

[7] V. Venkatesh, F. D. Davis, 2000. A Theoretical Extension of the Technology Acceptance Model: for longitudinal field studies. International Journal of Management Sciences, 46(2), pp 186-204.

[8] M. Fishbein, Ajzen, 1975. Belief, Attituder, Intention and Behaviour:AN Introduction to theory and Research. Reading,MA: Addison-Wseley.

[9] I. Ajzen, 1991. The theory of planned behavior. Organizational Behavior and Human Decision Processes, 50, pp 179-211.

[10] F. D. Davis, 1989. Perceived Usefulness, Perceived Ease-of-Use, and User Acceptance of Information Technology, MIS Quarterly, 13(3), pp. 319-339.

[11] D. L. Goodhue and R. L. Thompson, 1995.TaskTechnology and Individual Performance, MIS Quaterly, 19(2), pp 213-236.

[12] E. M. Rodgers, 2003. Diffusion of Innovation, 5th ed. New York. Free Press.

[13] H. C. Triandis, 1980. Values, Attributes and Interpersonal Behaviour. IN M.M Page Editor, Nebraska Symposium on Motivation, 1979. Beliefs, Attitudes and Values, University of Nebraska press, Lincoln, pp. 195259.

[14] E. H. Schein, Organizational Culture. WP 2088-88. Sloan School of Management Working Papers, Massachusetts Institute of Technology, 1988.

[15] A. Bandura, (1978). The self-system in reciprocal determinism. American Psychologist, 33, 344-358.

[16] A. Bandura, 1982. Self-efficacy mechanism in human agency. American Psychologist, 37 (1982), pp. 122-147

[17] J. D. Couger, (1986). Effect of Cultural Differences on Motivation of Analysts and Programmers: Singapore vs. the United States. MIS Quarterly, 10(2), 189-196.

[18] J. M. Choe, (2004). The Consideration of Cultural Differences in the Design of Information Systems. Information \& Management, 41, 669-684.

[19] S. Dasgupta, D. Agarwal, A Ioannidis, A. and S. Gopalakrishnan, (1999). Determinants of Information Technology Adoption: An Extension of Existing Models to Firms in a Developing Country. Journal of Global Information Management, 7(3), 30-40.

[20] D. R. Denison and A. K. Mishra, (1995). Toward a Theory of Organizational Culture and Effectiveness. Organization Science, 6(2), 204-223.

[21] C. Triandis, 1989. The self and social behavior in differing cultural contexts. Psychological review, Vol. 96, 3.
[22] K. C. Tibenderana, P. J Ogao, 2008. Information Communication technologies Acceptance and Use among university communities in Uganda: A model for Hybrid Library Services End-Users .pp 391-410.

[22] J. B. Miller, 1976. Towards a new Psychology of Women, beacon Press, Boston.

[23] H. L. Minton, F. W. Schneider, 1980. Differential Psychology Waveland Press, Prospect Heights,IL.

[24] A. Bandura, (1977). Social Learning Theory. Englewood Cliffs, NJ: Prentice Hall. 